\title{
Assessing a Two-Pronged Approach to Active Learning in Sport Sociology Classrooms
}

\author{
Emily Dane-Staples \\ St. John Fisher College
}

\begin{abstract}
Active-learning research has explored 2 distinct areas: pedagogy and physical space. As existing research has most often explored only 1 area per study and few have been done in the area of sport sociology, additional research is needed. This research combined both areas of active learning through a quasi-experimental design. Using 2 different classes, Sport and Society and Gender and Sport, students were exposed to an unchanging physical space or manipulated physical space, as well as activelearning tasks of varying complexity. No differences in student perceptions of engagement or learning were found when comparing space variations; however, task complexity did lead to significant differences in student perceptions of engagement and learning.
\end{abstract}

Keywords: classroom design, group design, student engagement

Using the definition of Miller and Metz (2014), active learning is an instructional method in which students become engaged participants in the classroom. However, this single definition does not make it easy to understand. Does this mean anything more than lecture? Does it require person to person interaction? What constitutes a classroom? These areas of confusion were confirmed by Patrick, Howell, and Wischusen (2016); where faculty, when asked to self-identify active learning practices, were hesitant to label activities based on a stated uncertainty of accurate labeling. The research shows that there are two main components of active learning that have an impact on student learning: the pedagogy of teaching and the physical space of learning.

Most commonly, the pedagogy of teaching and learning has been thought of as a primary influence over educational achievements. A passive student who only has to receive instructor information does not engage in a deep discussion of ideas nor has a requirement to ensure an accurate application of ideas, both requirements of long-term learning (Burke, Ahmadi, \& James, 2009; Garrett, 2016). Active learning strategies have been found to increase student engagement and success in learning spaces (Patrick et al., 2016). Active learning classrooms (ALCs) were found to be effective in promoting student collaboration and teamwork, discussion, and participation (Park \& Choi, 2014). In this way, active learning can help to facilitate improvement in "soft skills" in addition to growth in factual knowledge. The Active Learning Inventory Tool (ALIT) published by Van Amburgh, Devlin, Kirwin, and Qualters (2007) provides a comprehensive listing of active learning options to help instructors move students from passive to active in a classroom setting. However, the implementation of these active learning activities is shaped by spaces in which they can occur.

According to Park and Choi (2014), "educational spaces convey an image of educational philosophy about teaching and learning" (p. 750). Thus, the learning space symbolically and

The author is with the Sport Management Dept., St. John Fisher College, Rochester, NY. Address correspondence to edane-staples@sjfc.edu. silently influences a learning episode, which has prompted more educational institutions to consider the planning and construction of learning spaces (Jankowska \& Atlay, 2008; Zandvliet \& Broekhuizen, 2017). Despite the fact that classroom furnishings are often beyond instructor control, they have been found to partially influence student evaluations of instructor effectiveness (Safer, Farmer, Segalla, \& Elhoubi, 2005). In addition, seating placement is identified by students as preferred and nonpreferred areas that directly contribute to student perceptions of learning possibilities (Park \& Choi, 2014). Seating arrangements, whether student or instructor determined, are related to academic achievement, on-task behavior, and student-teacher interactions (van den Berg \& Cillessen, 2015). Therefore, when one attempts to assess learning achievements, the physical setting should be considered.

Teachers who trained years ago should recognize the need to update their thinking and strategies to address both 21 st century learners and 21st century learning environments (Madden, Wilks, Marone, Loader, \& Robinson, 2012). Even if this need is recognized, barriers such as choice in classroom and notification of classroom assignment, coupled with a lack of quality research that studies both strategies and spaces, may leave faculty hesitant to undertake significant changes despite their belief that changing to a learnercentered approach is in the best interest of students. Moving from an instructor-focused to a learner-centered environment requires changes in both the use of space and the interactions between people in the space (Madden et al., 2012). This being the case, it seems appropriate that a two-pronged approach to active learning should be considered to provide teachers a more complete strategy for meeting the demands of 21 st century education. Using an applied research design, this study explored how the manipulation of physical space and various typologies of active learning strategies were perceived by students in two classes that teach sport sociology content.

\section{Literature Review}

Building from constructivist learning theories, active learning puts students at the center of a learning process (Mangram, Haddix, Ochanji, \& Masingila, 2015). Constructivism stresses the need for 
students to construct their own understanding to deeply learn material, and active learning strategies help guide instructors in how to move away from the "teaching by telling" approach (Freeman et al., 2014). In response to the massification of higher education, where more and more people are feeling the need to have a higher education degree, universities are more often being asked to demonstrate the value of their programs (Mangram et al., 2015). Value in the form of meeting educational outcomes can be measured in a variety of ways, but all arise from a common denominator: how much learning occurred? In a traditional lecture classroom, it has been argued that only surface learning occurs; where students can memorize but not necessarily understand material (Yew et al., 2016). Active learning settings, where lecture is reduced and time is instead spent on cooperative work and engagement with material, have been shown to lead to deeper learning (Metzger, 2015).

Chi and Wylie (2014) propose a framework that links cognitive engagement to learning outcomes. Their framework of Interactive, Constructive, Active and Passive (ICAP) predicts, from most to least engaging, how learning occurs as a result of overt behaviors (Chi \& Wylie, 2014). Yew et al. (2016) assert that for deep learning to occur, students need to "relate concepts and ideas to existing experience, and critically evaluate the emerging knowledge for patterns and meanings" (p. 49). It is easy to see how the highest levels of engagement in the ICAP framework, interactive, and constructive, clearly map onto these contextual requirements. In using active learning rather than passive strategies, instructors become facilitators who ask good questions and design purposeful activities that guide students to construct meaning (Mangram et al., 2015).

\section{Active Learning}

Students can be actively engaged in learning both within and outside of classrooms. Research by Eagleman and McNary (2010) found that $77.5 \%$ of undergraduate sport management programs required an internship, and the Commission on Sport Management Accreditation requires those seeking accreditation to include components of both practical and experiential learning in their curricula (Hayes Sauder \& Mudrick, 2018). Experience-based learning as a form of active learning is common in sport management. Faculty also task students with being actively engaged outside of class so that learning within the classroom can be more active. The use of flipped classrooms (Killian \& Woods, 2018; Lumpkin \& Achen, 2015), blended learning (Bodary \& Gross, 2018), and team-based learning (Parr, 2013) are all pedagogical strategies that require students to be actively involved in the construction of their own knowledge both in and out of classrooms.

Focusing within the classroom, active learning strategies come in a variety of pedagogical options. "Written exercises, games, problem sets, i-clickers, debates, class discussions, etc." are all active learning strategies common in higher education classrooms (Patrick et al., 2016, p. 56). The 2-min paper or think-pair-share are not novel classroom tasks but are ones commonly used because they require student engagement with material (Mangram et al., 2015; Yew et al., 2016). Between tasks, the level of engagement and the complexity is not always equal, which is why hierarchical models related to active learning have been proposed.

The questioning hierarchy presented within Mangram et al. (2015) outlines ways that instructors can scaffold questions to achieve particular outcomes. Beginning at the entry level, that is, history, and moving to the highest level, that is, explanation, each phrase requires activation of prior information, moving students to an active role in the classroom (Table 1). At the highest level of questioning, students are being asked to explore unstated information, which is a highly complex task. The ALIT provides additional assistance for instructors who wish to assess how various active learning strategies vary in complexity (Van Amburgh et al., 2007). As seen in Table 2, ALIT maps 22 different possible classroom activities to a range of complexity classifications (11 low complexities, seven moderate complexities, and four high complexities). Validated through multiple rounds of expert review and applied observer analysis, the tool affords instructors pedagogical options to actively engage students (Van Amburgh et al., 2007). Used for the planning of activities, the range of complexity levels available encourages instructors to select active learning strategies that might be most successful given different contexts of learning such as classrooms with first-year or fourth-year students, early versus late in the term, or when working with novel or well-established content.

The use of active learning strategies has demonstrated positive effects on knowledge acquisition. In prior studies, both individual assignment grades and final grades were shown to be improved within an ALC compared with a traditional, lecture-based class (Brooks \& Solheim, 2014; Freeman et al., 2014). Active learning can also address the demand for nonknowledge-based abilities, sometimes referred to as soft skills (Bodary \& Gross, 2018). By engaging with peers and having to clearly articulate one's own ideas, students are given opportunities to strengthen their abilities of critical thinking and working in teams (Bodary \& Gross, 2018).

\section{Table 1 HRASE Questioning Hierarchy}

\begin{tabular}{|c|c|c|}
\hline Area & Outcome goal & Example questions \\
\hline History & $\begin{array}{l}\text { Questions that relate } \\
\text { to students' } \\
\text { experience }\end{array}$ & $\begin{array}{l}\text { What did you do ... ? } \\
\text { What happened when you ... ? } \\
\text { What happened next ...? } \\
\text { How did you feel when . . . ? }\end{array}$ \\
\hline Relationships & $\begin{array}{l}\text { Questions that } \\
\text { engage students in } \\
\text { comparing ideas, } \\
\text { activities, data, etc. }\end{array}$ & $\begin{array}{l}\text { How does this compare to ....? } \\
\text { What else does this relate to ...? } \\
\text { What do all these procedures have } \\
\text { in common ...? } \\
\text { In what ways is this easier/more } \\
\text { difficult than ... ? }\end{array}$ \\
\hline Application & $\begin{array}{l}\text { Questions that } \\
\text { require students to } \\
\text { use knowledge in } \\
\text { new contexts }\end{array}$ & $\begin{array}{l}\text { How could this idea be used to } \\
\text { design ... ? } \\
\text { What recognized revenue issues } \\
\text { could this solution solve? } \\
\text { What evidence do we have that } \\
\text { supports? }\end{array}$ \\
\hline Speculation & $\begin{array}{l}\text { Questions that } \\
\text { require thinking } \\
\text { beyond given } \\
\text { information }\end{array}$ & $\begin{array}{l}\text { What would happen if you } \\
\text { changed ... ? } \\
\text { What might the next appropriate } \\
\text { step be ...? } \\
\text { What potential problems may } \\
\text { result from ...? } \\
\text { How would [stakeholder] react } \\
\text { if . . . ? }\end{array}$ \\
\hline Explanation & $\begin{array}{l}\text { Questions that get at } \\
\text { underlying reasons, } \\
\text { processes, and } \\
\text { mechanisms }\end{array}$ & $\begin{array}{l}\text { How does that work? } \\
\text { How can we account for ... ? } \\
\text { What justification/s could be } \\
\text { provided for . . . ? } \\
\text { What assumptions are being made } \\
\text { about . . .? }\end{array}$ \\
\hline
\end{tabular}

Note. Adapted from "Active Learning Strategies for Complementing the Lecture Teaching Methods in Large Classes in Higher Education," by J.A. Mangram, M. Haddix, M.K. Ochanji, and J. Masingila, 2015, Journal of Instructional Research, 4, pp. 57-68. 


\section{Table 2 Active Learning Inventory Tool}

\begin{tabular}{|c|c|}
\hline Task & Activity description \\
\hline \multicolumn{2}{|c|}{ Low Complexity } \\
\hline A & Question \& answer - students orally respond to a question, comment, etc. by either cold-calling or voluntarily responding. \\
\hline $\mathrm{B}$ & Focused Listing, One Sentence Summary, One-minute Paper-short writing task designed to allow students to focus attention. \\
\hline $\mathrm{C}$ & $\begin{array}{l}\text { Think/Pair/Share-short, individual written response to a prompt/question; then instructed to share and discuss briefly with } \\
\text { partner, then asked to share with larger group. }\end{array}$ \\
\hline $\mathrm{D}$ & Brain Dump/Free Write-short write in which students write down everything they know about an announced topic. \\
\hline $\mathrm{E}$ & $\begin{array}{l}\text { Muddiest Point—at some point during or after an in-class presentation; students write a quick response to the prompt "What } \\
\text { was the muddiest point in }\end{array}$ \\
\hline $\mathrm{F}$ & $\begin{array}{l}\text { Misconception/Preconception Check-simple technique for gathering information on what students perceive they already } \\
\text { know. }\end{array}$ \\
\hline G & Application Activity-written activity in which students apply one to two principles and concepts to a real-life situation. \\
\hline $\mathrm{H}$ & Student-Generated Questions-students create quizzes or exams that are crafted to capture central elements of the course. \\
\hline I & Formative Quizzes/Surveys (Background Knowledge Probe)—ungraded quizzes/surveys to determine comprehension. \\
\hline $\mathrm{J}$ & $\begin{array}{l}\text { Computer Based Interaction Systems (Personal response system)—students participate in the lecture by responding to } \\
\text { questions/statements via computers/wireless technology. }\end{array}$ \\
\hline $\mathrm{K}$ & $\begin{array}{l}\text { Self/Peer Formative Assessment-activities that require students to assess performance against applicable criteria; extend to } \\
\text { offer specific suggestions for improvement. }\end{array}$ \\
\hline \multicolumn{2}{|c|}{ Moderate Complexity } \\
\hline $\mathrm{L}$ & Small Group Present/Discuss-presentations and discussions of course material led by faculty or students. \\
\hline M & $\begin{array}{l}\text { Role Playing/Simulations/Games—students and/or faculty performing specific roles for demonstration purposes. Simulations/ } \\
\text { games include guiding principles, specific rules, and structured relationships. }\end{array}$ \\
\hline $\mathrm{N}$ & $\begin{array}{l}\text { Categorizing Grid/Pro-Con Grid—students are presented with two to three important categories (superordinate concepts) } \\
\text { along with scrambled subordinate terms, images, equations, or other items that belong in one or another of the superordinate } \\
\text { categories. }\end{array}$ \\
\hline $\mathrm{O}$ & $\begin{array}{l}\text { Defining Features Matrix/Memory Matrix—students categorize concepts presented according to presence }(+) / \text { absence }(-) \text { of } \\
\text { defining features }\end{array}$ \\
\hline $\mathrm{P}$ & Debates—small or large group structured exploration of central concepts, data, beliefs, and values \\
\hline Q & Peer Teaching—students teaching each other basic and/or intermediate levels of course materials or needed skills. \\
\hline $\mathrm{R}$ & $\begin{array}{l}\text { Concept Maps-drawings or diagrams that show the mental connections that students make between a major concept } \\
\text { presented and other concepts they have learned. }\end{array}$ \\
\hline \multicolumn{2}{|c|}{ High Complexity } \\
\hline $\mathrm{S}$ & Cases-scenarios that require students to integrate their skills to solve problems that relate to course material. \\
\hline $\mathrm{T}$ & $\begin{array}{l}\text { Cooperative Cases_-scenario-based problem solving activity using small groups to tackle specific questions/issues from larger } \\
\text { list. }\end{array}$ \\
\hline $\mathrm{U}$ & $\begin{array}{l}\text { Jigsaw-team-based; each member becomes subject matter expert in one of } 4 \text { areas selected from current course material. Each } \\
\text { member teaches their subject matter. }\end{array}$ \\
\hline V & Cooperative Learning/Problem Based Learning—students work together to learn course knowledge and develop course skills. \\
\hline
\end{tabular}

Note. Table contents used with permission from Van Amburgh, J.A.V., Devlin, J.W., Kirwin, J.L., \& Qualters, D.M. (2007). A tool for measuring active learning in the classroom. American Journal of Pharmaceutical Education, 71(5), 1-85.

The increased proficiency in these soft skills is often mentioned by students when assessing their perceptions of an active learning environment (Lumpkin, Achen, \& Dodd, 2015b). Through these studies, it is clear that actual and perceived learning of content, an opportunity to develop soft skills, and increased engagement are all present in classrooms that use active learning techniques.

When students enjoy an activity, whether or not it is actually impacting their grades, their engagement will increase (Komarraju $\&$ Karau, 2008). As engagement is a prerequisite for learning, it is logical to assess student perceptions of engagement related to active learning strategies. Research by Lumpkin, Achen, and Dodd (2015a) found that six of the eight in-class active learning strategies tested were perceived by at least $50 \%$ of students to often have a positive impact on their learning. In an additional study, for all seven strategies assessed, no greater than $10 \%$ of students responded that any one activity never had an impact on their learning (Lumpkin \& Achen, 2015). It appears that student perception of impacts on learning will vary based on activity but that active learning strategies are working with a majority of students. The following hypotheses are proposed:

H1: Tasks of various complexities will have differences in student perceptions of engagement.

H2: Tasks of various complexities will have differences in student perceptions of learning.

\section{Physical Spaces for Active Learning}

Prior to 1995, many social psychologists studying educational contexts did not explore how physical distance can be a moderator of social interaction (Latane, Lou, Nowak, Bonevento, \& Zheng, 
1995). This omission was flawed; a classroom is a confined space where social actors are consistently engaged for an extended period of time. More recent research has demonstrated the effects of physical proximity on interpersonal contact and the development of social relations (van den Berg \& Cillessen, 2015). As such, the science of teaching and learning should consider how social spaces and physical distance as a result of classroom design might be impacting learning. Ecological psychology argues that students are information detectors who understand what an environment affords and recognize the possibilities for action in a particular space $(\mathrm{Ge}$, Yang, Liao, \& Wolfe, 2013). In this way, students are aware of what a classroom space affords them.

There is no perfect classroom design that can accommodate all types of academic activities; space can either enable or inhibit various styles of teaching and learning (Lei, 2010; Park \& Choi, 2014). Despite the fact that learning spaces and classroom furnishings are almost always beyond instructor control, they have been found to partially influence student evaluations and learning outcomes (Safer et al., 2005). Jankowska and Atlay (2008) identify three different categories of learning spaces: the Social Learning space (S-space), the Formal space (F-space), and the Creative space (C-space). Although most schools are focused on the f-spaces like traditional classroom and computer labs, many schools are beginning to focus on these other learning spaces where students are in a more relaxed setting and that objects are provided to them that encourage further engagement with both their peers and the material presented outside of the F-space (Jankowska \& Atlay, 2008). Research within sport management has explored spaces beyond the classroom to include experiential learning sites, club activities and management, and volunteer experiences (see Diacin, 2018; Judge et al., 2011; Pate \& Shonk, 2015). These studies and others have demonstrated the value of new learning spaces due to the limitations present within traditional classrooms.

Traditional classroom designs are the row and column or auditorium-style seating that places the instructor as the focal point at the front of the room (Cotner, Loper, Walker, \& Brooks, 2013; Petersen \& Gorman, 2014). Chairs that are bolted in place emphasize the instructor over the student and challenge the natural formation of groups for learning (Cotner et al., 2013). In these traditionally designed spaces, students are physically close but often intellectually separate from their peers and from the instructor. Classrooms that are deeper than they are wide create great physical separation between instructor and student. In these settings, students rated their satisfaction with instructor performance lower than in differently designed classrooms (Safer et al., 2005).

As students spend most of their time learning in classrooms, they are consistent consumers of these spaces (Park \& Choi, 2014). Classroom features influence both students learning and instructor pedagogies, and this is implicitly understood by classroom stakeholders (Ge et al., 2013). Seating arrangements, whether student or instructor determined, are related to academic achievement, on-task behavior, and student-teaching interactions (van den Berg \& Cillessen, 2015). Across many academic disciplines and in a variety of classes, consistency is found in preferred seating locations by students (Park \& Choi, 2014). The "Golden Zone" (Park \& Choi, 2014) is identified as the seating that is just behind the first row and clustered in a diamond shape about the center of the room was labeled by students to be the optimal place for good instructor eye contact, an ideal place to receive minimal distraction from peers, and best view of the screen or whiteboard. Classrooms in the traditional layout leave the majority of students in a shadow zone (outside the "Golden Zone"), physically separate from their peers and from the instructor, where social interaction is minimal. Effective space utilization (i.e., classroom redesign) can bridge the gap between lecturers and students (Jankowska \& Atlay, 2008). By just changing the physical space, there is a reduction in formality between student and instructor, which most students find beneficial.

"We know too much about how learning occurs to continue to ignore the ways in which learning places are planned, constructed, and maintained" (Van Note Chism, 2002, p. 5). Universities are beginning to utilize new classroom designs to maximize educational outputs (Park \& Choi, 2014). Newly designed ALCs reject the traditional design of independent desks in favor of round tables where students can maximize face time with their peers, essentially turning an F-space into an S-space (Jankowska \& Atlay, 2008; Lei, 2010). These redesigns also move the instructor from the front of the room to the center of it (see Figure 1). ALC's furniture arrangement and overall design can transform the instructor from the information transmitter to the facilitator (Ge et al., 2013). Multiple whiteboards are placed throughout the room's walls

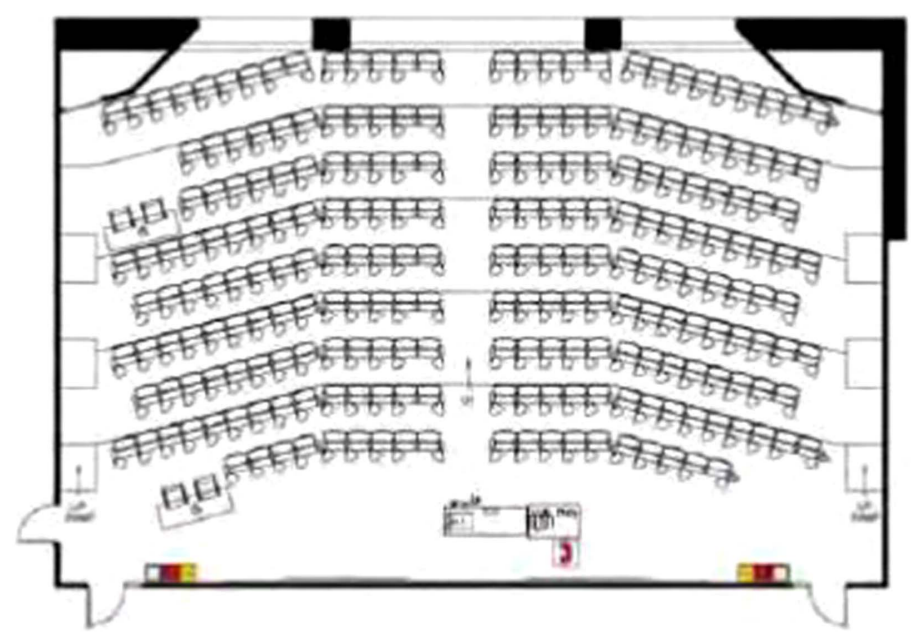

Traditional classroom layout

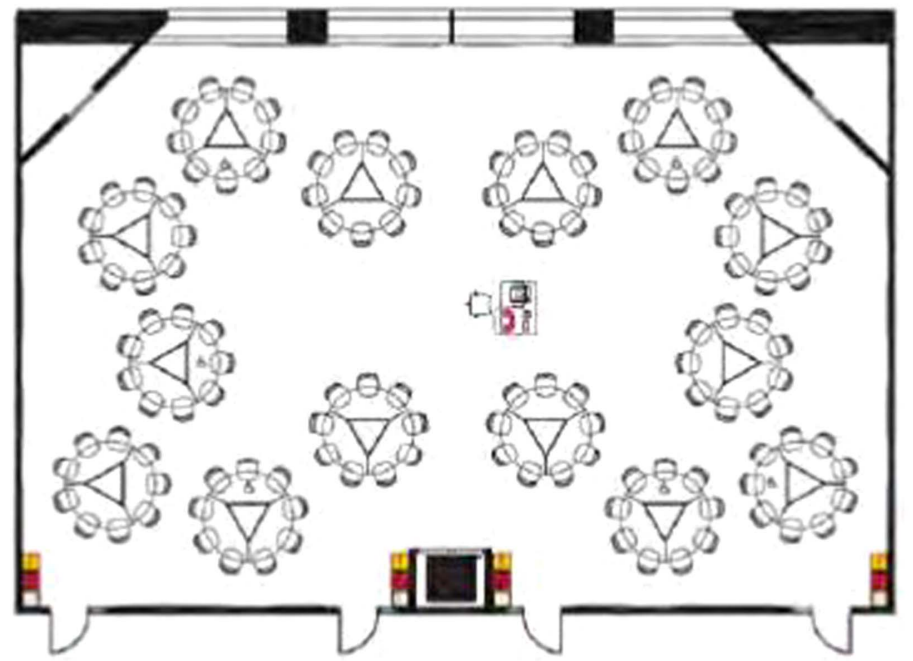

Active learning classroom layout

Figure 1 - Traditional versus active learning classroom layout. Images reprinted with permission from Cotner, S., Loper, J., Walker, J.D., \& Brooks, D.C. (2013). 'It's not you, it's the room'-Are the high-tech, active learning classrooms worth it? Journal of College Science Teaching, 42(6), 82-88. 
where individual groups have their own spaces to work and share their responses (Petersen \& Gorman, 2014). There have been positive results from these redesigns. Students in modified (redesigned) versus traditional row/column classrooms had lower failure rates and increased levels of understanding (Cotner et al., 2013; Freeman et al., 2014). If universities have yet to invest in these spaces, instructors are left to work with what is available. Moving desks together to facilitate group work is common as is arranging tables into a conference room design. However, the time it takes to arrange the desks or tables into the preferred format, and then return them, eliminates class time that could be spent engaged in learning activities. The following hypotheses are proposed:

H3: A class with high seating variation in its use of physical space will have higher student perceptions of engagement than a static seating classroom.

H4: A class with high seating variation in its use of physical space will have higher student perceptions of learning than in a static seating classroom.

\section{Purpose}

The study by Brooks and Solheim (2014) was distinctive in that they tested for the impact of the ALC (physical space) in addition to the pedagogies. Both physical and social factors within the realm of learning influence the process and experience of learning for students (Zandvliet \& Broekhuizen, 2017). For this reason, more applied research needs to combine the variable of physical space into research on active learning pedagogies. Smith (2015) calls on faculty who attempt active learning implementation to engage in greater reflection and assessment of their practices in ways that treat class activities as unique entities to more accurately report successful and unsuccessful practices. In their call to action, Lumpkin et al. (2015b) encourage faculty to evaluate their teaching strategies and solicit anonymous student perceptions as a quality mechanism to improve course design and instructional strategies. The purpose of this project is to engage in this reflective practice and to assess both the manipulation of physical space and pedagogical activities in two classrooms that teach sport sociology content.

\section{Methods}

\section{Study Design}

This was a quasi-experimental design that conducted applied research in two different 200-level courses that covered sport sociology concepts: Sport and Society and Gender and Sport. Both classes were taught by the same instructor during the same semester and had additional similar attributes, making them ideal for inquiry. Both classes had been taught consistently at the institution for more than 5 years and each fulfilled a dual role in the curriculum, meeting both an elective requirement for sport management majors as well as a general education requirement for any enrolled undergraduate student. However, some differences should be noted. Sport and Society was taught as a traditional faceto-face course 2 days a week for 80 min each. Gender and Sport was taught as a hybrid class. The class met for 55 min on Monday and Wednesday of each week, but only met one Friday per month for the same time block. Online activities through the institution's learning management system were substituted for the Friday sessions where face-to-face instruction did not occur.
The quasi-experimental design component was the manipulation of the physical space in the two classes. Sport and Society used group membership cards to rotate classroom seating and groupings each class period. At the outset of the semester, each student was given a membership card which had a number of markings that would divide the entire class into various group sizes. Based on what the instructor had planned for the day, a notation on the board was made indicating what groups students should be in. After observing the notation upon entering the classroom, students would divide into group sizes ranging from three to six members and move their desks together. In this way, students are exposed to different placements within the classroom, number of group members, and peer interactions each class period. Until the class began, students were unsure of how the desks would be arranged and the physical space manipulated. By contrast, Gender and Sport had no daily manipulation of physical setting nor group membership. Upon entering the classroom, "pods" of four or five desks were already in place and students self-selected their own groups. As commonly happens, seats that students took in the first few weeks of the semester became their "permanent" seat and consequently, group membership. Only three times during the first half of the semester the instructor intentionally disrupted the student-selected groups. These disruptions were done to better align with the class activities for the day that involved homogeneous groups, independent work, or larger group discussions. In both classes, a variety of active learning strategies were utilized throughout the semester coupled with instances of lecture. Any lecture that occurred was paired with class activities and took place while students were in the physical space arrangement. The instructor planned activities without a priori consultation of the ALIT and instead designed activities based on content needs and instructional experience.

Research protocols were approved by the St. John Fisher College institutional review board with the data-collection point being just after the midterm point in the semester for both classes. At the beginning of a regular class session, the instructor read the consent statement, distributed the surveys to the class, and then left the room. A student volunteer collected all of the surveys after they were completed and returned them to the researcher who was waiting outside of the class. No inducements to participate were made by the researcher, and students were told participation was optional.

\section{Population and Sample}

As students self-enrolled in these courses, no specific sampling was done. Sport and Society had 30 students, 28 of whom opted to provide feedback at the data collection point. Of the 30 students in the class, the majority were male $(87 \%)$, sport management majors (70\%), and were spread almost evenly throughout all academic years (eight freshman, eight sophomore, 10 juniors, and four seniors). No respondent demographics were collected on the instrument itself to protect the identity of the students. Gender and Sport had 24 students, 21 of whom completed the survey instrument. The demographics of this class were substantially different than those of Sport and Society. In the Gender and Sport class the majority were women $(58 \%)$, nonsport management majors (79\%), and heavily populated by sophomores and juniors (no freshman, 10 sophomores, 12 juniors, and two seniors). Again, no respondent demographics were collected to protect the small number of enrolled students.

\section{Survey Instruments}

Two different surveys specific to each course were developed to assess the two-pronged approach to active learning. The questions 
in both surveys were similar, with modifications made to account for the differences in physical layout and for the specific active learning strategies used. The surveys included both quantitative and qualitative measures as a more accurate method to gather student perceptions (Lumpkin \& Achen, 2015; Lumpkin et al., 2015a). Each survey had two distinct question sections: one about the physical space and one about pedagogy. The physical space portion modified questions from the School, Physical, and Campus Environment Survey instrument designed by Zandvliet and Broekhuizen (2017) and contained four questions. The original instrument demonstrated acceptable discriminant validity measures and a Cronbach alpha greater than .7 (Zandvliet \& Broekhuizen, 2017). The first two physical space questions asked students to comment on their group formations and movements (or lack thereof for Gender and Sport) and their perceptions on how this impacted their learning and engagement. The third question was similar for both instruments and asked students to report on the conditions of the classroom (lighting, seating, temperature, etc.) impacting their learning. The fourth question in the physical space section of the survey was different for both classes. For Gender and Sport, a specific question was asked about the virtual learning space as it was a hybrid course. The Sport and Society instrument, without this additional space aspect, included a more general question about what could be altered in the physical space of the classroom to improve student learning.

The pedagogy portion of the survey instruments combined aspects of two instruments. The individual questions were the ALIT activities unique to each of the two classrooms (Van Amburgh et al., 2007). As the labels identified in the ALIT are generic descriptions and lack clarity for students, the specific activities done in class were listed on the survey instrument without any reference to ALIT classification. The ALIT was validated through expert reviewers, and instrument modifications that resulted in the identification of active learning strategies and final rank order of strategies as low, moderate, or high complexity (Van Amburgh et al., 2007). The scale from the Active Learning Survey designed by Monson (2005) was a 5-point scale of 1 (not effective) to 5 (highly effective); students were asked to rate their perception of each pedagogical technique in two areas. The first area was the technique's effectiveness in helping them engage with the material, and the second was the technique's effectiveness in helping them learn or clarify materials. Sport and Society had nine active learning techniques listed, one nonactive learning technique (lecture with PowerPoint), and two open-ended options where students could write in other activities that they felt were part of their learning. Gender and Sport had the same number of pedagogical prompts, but five were different techniques specific to the class content. The Gender and Sport class also had the nonactive learning prompt and the writein options. Each instrument had a total of 10 specific activities respondents rated on perceptions of engagement and perceptions of facilitating learning with two optional write-in areas (Table 3).

Within the list of learning techniques on each instrument, those that were identified by the ALIT as "active learning" (regardless of complexity level) were labeled with an asterisk. Following the rating scale items, four additional questions were asked to help identify student preferences. The first closedquestion asked students to consider the list of pedagogies and indicate which they prefer: only one or two of them or if they prefer the variety of techniques. An open-ended question came next, asking which two strategies helped them learn the best. Finally, students were asked to indicate their preference for the remainder of the semester as either being more active learning with less lecture, mostly the same amount of active learning and lecture, or more lecture with less active learning. The closing question of both instruments was open-ended and asked students to provide any feedback they wished to share about the course or its delivery to that point in the semester.

\section{Data Analysis}

To prepare data for analysis, additional coding was needed for the quantitative data. In the survey instrument, all active learning techniques were labeled without regard for complexity. As the researcher wished to assess the possibility of complexity compounding student responses, all techniques were further labeled according to the ALIT as either low, moderate, or high-complexity tasks, with lecture and PowerPoint serving as the baseline for zero complexity. Within Sport and Society, five activities were rated as low complexity, two as moderate, and two as high complexity. For Gender and Sport, four activities were rated as low complexity

\section{Table 3 Classroom Activities as Mapped to the Active Learning Inventory Tool}

\begin{tabular}{|c|c|c|c|}
\hline & & Sport and society & Gender and sport \\
\hline A & Question and answer & PowerPoint-prompted questions & PowerPoint-prompted questions \\
\hline B & Focused listing & $\begin{array}{l}\text { Thinking questions with readings and } \\
\text { in-class reading check }\end{array}$ & \\
\hline G & Application activity & Worksheets with discussion & Worksheets with discussion \\
\hline I & Formative quizzes & IF-AT team quizzes & Online quizzes IF-AT team quizzes \\
\hline $\mathrm{J}$ & Computer-based interaction & Poll everywhere session & \\
\hline $\mathrm{L}$ & Small-group present/discuss & $\begin{array}{l}\text { Selection of film/clips with student-led } \\
\text { discussion }\end{array}$ & $\begin{array}{l}\text { Presentation of gendered commercial } \\
\text { with student-led discussion }\end{array}$ \\
\hline $\mathrm{O}$ & Defining features matrix & & $\begin{array}{l}\text { Gender continuum } \\
\text { Gender label posters }\end{array}$ \\
\hline $\mathrm{P}$ & Debates & & Root issue identifications \\
\hline $\mathrm{T}$ & Cooperative cases & $\begin{array}{l}\text { Title IX compliance cases with Equity in } \\
\text { Athletics Disclosure Act data sets }\end{array}$ & \\
\hline $\mathrm{U}$ & Jigsaw & Group essays and case study & \\
\hline
\end{tabular}

Note. Any blank cell indicates that a task of that classification was not conducted in that course. IF-AT = immediate feedback assessment technique. 
and five were rated as moderate complexity; no tasks were labeled high complexity.

As both quantitative and qualitative data were present, multiple techniques were used for analysis. Thematic coding was applied to the open-ended questions with a constant comparison method utilized (Bower, Hums, \& Grappendorf, 2015). For each question, comments were first organized based on common word choice in labeling of opinions and activities. Students describing the same activities or ideas were initially grouped, and then the researcher reviewed the comments again to determine if alternative word choice was used to describe a similar sentiment. For the final question, responses were grouped based on the interpretation of the prevailing sentiments expressed by the student's own words (Lumpkin \& Achen, 2015). Data were input into SPSS (version 24; IBM Corp., Armonk, NY) to calculate the mean effectiveness scores for each pedagogy for both engagement and learning scores. In addition, frequencies were calculated for pedagogy preferences to date and pedagogy preferences for the remainder of the term. Inferential analysis included analysis of variance to test for differences in task complexity ( $\mathrm{H} 1$ and $\mathrm{H} 2)$ and independent $t$ tests to assess differences in physical space manipulation (H3 and $\mathrm{H} 4)$.

\section{Results}

This quasi-experimental study explored the effectiveness of variations in physical space and active learning techniques in two sport sociology classrooms. Although both classrooms moved beyond the traditional row and column seating arrangement, the Sport and Society classroom had consistent variations in group size and composition, whereas the Gender and Sport classroom had consistency in both areas. Both classrooms utilized a variety of active learning pedagogies ranging from zero complexity (lecture with PowerPoint) to higher complexity tasks. The hypotheses were tested using quantitative methods, and the findings were supplemented using the qualitative data. Student responses show that both physical space and active learning techniques were perceived to have an impact on their engagement with and learning of material, although only some were statistically significant.

\section{Assessing the Impact of Task Complexity}

Tasks that are moderately complex had the highest effectiveness averages for both engagement and learning across both classes (Table 4). Although two of the low-complexity tasks, application activities (ALIT Task G) and computer-based interactions (ALIT Task J), also had some scores in the very effective range, most tasks were rated only of average effectiveness. Statistical tests for $\mathrm{H} 1$ and $\mathrm{H} 2$ showed that student perceptions of engagement, $F(3,482)=$ $13.464, p<.01$, and perceptions of learning, $F(3,480)=8.674$, $p<.01$, were significantly different for tasks of various complexities. Different levels of complexity in task design were perceived by students to have different impacts on their engagement and learning.

The focused qualitative question asking students by which methods they learned best were the same for both classes, application activity (ALIT Task G, low complexity) and small group present/ discuss (ALIT Task L, moderate complexity), which supports the quantitative data. Students across both classes $(n=41)$ indicated that they preferred the variety of tasks rather than limiting techniques to one or two. Almost half of the students $(n=27)$ indicated that the current mix of active engagement and lecture was desirable, whereas 17 students indicated that they would like even more active learning techniques used in class. Only one student between the two classes (coming from Sport and Society) indicated that they would prefer more lecture with fewer active learning techniques.

\section{Assessing the Impact of Physical Space}

The final two hypotheses tested the use of physical space on perceptions of engagement and learning; Table 4 presents the

\section{Table 4 Combined Class Descriptive Statistics of Perceptions of Engagement and Learning of ALIT Tasks}

\begin{tabular}{|c|c|c|c|c|c|}
\hline & & \multicolumn{4}{|c|}{ Student perception ratings } \\
\hline & & \multicolumn{2}{|c|}{$\begin{array}{l}\text { Effective for } \\
\text { engagement }\end{array}$} & \multicolumn{2}{|c|}{ Effective for learning } \\
\hline & & $\boldsymbol{\mu}$ & $S D$ & $\boldsymbol{\mu}$ & $S D$ \\
\hline \multicolumn{2}{|c|}{ Lecture with PowerPoint } & 3.28 & 1.090 & 3.45 & 1.120 \\
\hline \multicolumn{6}{|c|}{ Low-complexity tasks } \\
\hline A & Question and answer & 3.75 & 0.804 & 3.73 & 0.811 \\
\hline $\mathrm{B}$ & Focused listing & 3.80 & 1.020 & 3.89 & 0.994 \\
\hline G & Application activity & 4.12 & 0.807 & 4.08 & 0.759 \\
\hline I & Formative quizzes & 3.70 & 1.010 & 3.49 & 1.100 \\
\hline $\mathrm{J}$ & Computer-based interaction & 4.04 & 1.080 & 3.73 & 1.220 \\
\hline \multicolumn{6}{|c|}{ Moderate-complexity tasks } \\
\hline $\mathrm{L}$ & Small group present/discuss & 4.22 & 0.806 & 4.20 & 0.853 \\
\hline $\mathrm{O}$ & Defining features matrix & 4.24 & 1.010 & 4.10 & 1.140 \\
\hline $\mathrm{P}$ & Debates & 4.15 & 0.875 & 4.05 & 1.050 \\
\hline \multicolumn{6}{|c|}{ High-complexity tasks } \\
\hline $\mathrm{T}$ & Cooperative cases & 3.81 & 0.962 & 3.77 & 1.030 \\
\hline $\mathrm{U}$ & Jigsaw & 3.79 & 0.983 & 3.57 & 1.290 \\
\hline
\end{tabular}


mean effectiveness scores and SDs for both classes on all the pedagogical techniques. Across all task types, the student perceptions of engagement and of learning for both classes fell into the average effectiveness level $\left(\mu_{\text {Engagement }}=3.91 ; \mu_{\text {Learning }}=3.85\right)$. The data for each class separately can be seen in Table 5. A $t$ test done to assess differences in student perceptions of engagement between classes was not significant, $t(456)=.889 ; p>.05$; Cohen $d=-0.0812$. The fourth hypothesis was rejected as no differences were found in comparing student perceptions of learning, $t(456)=-1.815 ; p>.05$; Cohen $d=-0.1661$. In this experiment, there were no differences in perceptions of engagement or learning across various uses of physical space. Further insight into these rejections can be explored using the qualitative responses.

For Sport and Society, the majority of students indicated that they liked the different groups $(n=22)$ and that moving around kept them fresh and engaged $(n=10)$. A few students even mentioned that they would like some additional group formation possibilities instituted so that they could engage with different classmates. Only two respondents indicated that the changes felt chaotic to them and wished for a little more consistency. As expected, the movement caused challenges regarding space. Several students indicated that sight lines were impacted when group work and instructor directed content were blended in a single class session, and it was "sometimes hard to see around and over people." What was good for one activity was not optimal for another, causing students to have to continue to adjust their placement. Three students mentioned that they wished for tables instead of desks to make the transition to group work easier. Approximately one-third of the students mentioned additional issues with physical space of the classroom including the temperature, a distracting dry erase marker mark on the projector screen, and the bland color of the walls.

Gender and Sport had less consistency in qualitative responses about the physical space. Five students wrote about their increased comfort level with the same group and physical placement in the classroom, and two others indicated "the same grouping helps me to feel comfortable even when I don't want to share with the whole class." Two students wished for a greater variation in group formation as they felt "restricted from having smaller discussions with new others." One comment was indicative of this split when they wrote "I don't mind on occasion (emphasis added), good to talk to different people." Gender and Sport students were similar to Sport and Society in their frustration with desks rather than tables $(n=5)$ and sightlines as tasks changed, but also mentioned the pods were "better than traditional rows." However, this comment about traditional rows was refuted by another student who felt restricted from having their own private space as all physical arrangements had students in close proximity to others.

Across both classes, the consistent arrangement of the physical space into groups seemed to be preferred by students. Specific to engagement with other people, students wrote about the ease with which they talked to the large group because they had done the small group discussion first. They discussed the pleasure in meeting new people, identifying everyone's strengths, and having the ability to interact with others to whom they normally do not speak. Similarly, students found greater engagement with the material when they worked with others. Students reported that they can "get more perspectives," "expand my mind and get more opinions," and that working in groups helps to "spark new ideas and conversation."

Students also reported specific learning impacts due to the physical placement into groups. One student reported that it "makes me study harder because I don't want to be the worst one" and that working in groups makes it "more efficient to conquer an assignment." Across both classes, about half of the students indicated that the group work led to deeper discussion and understanding of ideas.

\section{Discussion}

Madden et al. (2012) found that the use of space plus pedagogy created opportunities to motivate and engage students in a learning process. The current study provides important evidence to further support this two-pronged approach to active learning. Perceptions

\section{Table 5 Mean Perceptions of Effectiveness Scores for Pedagogical Tasks}

\begin{tabular}{|c|c|c|c|c|c|}
\hline & & \multicolumn{4}{|c|}{ Mean student perception ratings } \\
\hline & & \multicolumn{2}{|c|}{ Effective for engagement } & \multicolumn{2}{|c|}{ Effective for learning } \\
\hline & & Sport and society & Gender and sport & Sport and society & Gender and sport \\
\hline Lect & vith PowerPoint & 3.30 & 3.24 & 3.43 & 3.48 \\
\hline \multicolumn{6}{|c|}{ Low-complexity tasks } \\
\hline A & Question and answer & 3.86 & 3.62 & 3.75 & 3.71 \\
\hline B & Focused listing & 3.80 & & 3.89 & \\
\hline G & Application activity & 4.29 & 3.90 & 4.14 & 4.00 \\
\hline I & Formative quizzes & 3.68 & $3.72^{\mathrm{a}}$ & 3.36 & $3.57^{\mathrm{a}}$ \\
\hline $\mathrm{J}$ & Computer-based interaction & 4.04 & & 3.73 & \\
\hline \multicolumn{6}{|c|}{ Moderate-complexity tasks } \\
\hline $\mathrm{L}$ & Small group present/discuss & $4.11^{\mathrm{a}}$ & $4.39^{\mathrm{a}}$ & $4.03^{\mathrm{a}}$ & $4.43^{\mathrm{a}}$ \\
\hline $\mathrm{O}$ & Defining features matrix & & $4.24^{\mathrm{a}}$ & & $4.10^{\mathrm{a}}$ \\
\hline $\mathrm{P}$ & Debates & & 4.15 & & 4.05 \\
\hline \multicolumn{6}{|c|}{ High-complexity tasks } \\
\hline $\mathrm{T}$ & Cooperative cases & 3.81 & & 3.77 & \\
\hline $\mathrm{U}$ & Jigsaw & 3.79 & & 3.57 & \\
\hline
\end{tabular}

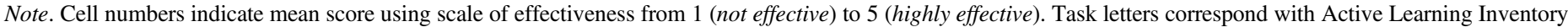
Tool instrument classification. Any blank cell indicates that a task of that classification was not conducted in that course

${ }^{\mathrm{a}}$ An average effectiveness score for two separate tasks of this type. 
of engagement in the learning process and with peers were clearly evident in this study. Specific to Gender and Sport, the option for students to self-select into a seating placement and group membership that they are comfortable with established their physical proximity to selected others. As group work progressed, each group became more socially connected; as one student indicated, "I love my pod." This supports findings that demonstrate the effects of physical proximity on interpersonal contact; the development of social relations (van den Berg \& Cillessen, 2015); and memorable interactions (Latane et al., 1995). That is, more memorable interactions are recalled by those whom we come in contact with. In these two classrooms, group members became both the constructors and recipients of memorable interactions due to their physical proximity to others.

Active-learning interactions between group members required the use of communication skills and the ability to work with others. Students in both classes made reference to the value in hearing from others, working collectively on assignment completion, and the power of the team in generating ideas. Although not measured directly, this utilization and possible development of interpersonal skills is a welcome by-product of active learning strategies and supports the conclusions of Park and Choi (2014).

Researchers have found that appropriate use of an ALC depends on course content and class size (Ge et al., 2013), which was found to be true here as well. It is possible that the subject differences between the two classes contributed to the effectiveness of both physical space variations. Gender and Sport is a more contentious subject and one that students are generally a bit hesitant to engage with. It is reasonable to presume that the complex, sometimes controversial, material presented in the large setting was mitigated by the ability of students to work through the material with people they were comfortable with. That is, because the groups were unchanging and social relationships were well established, students felt comfortable discussing the material. Perhaps the consistent group variation worked well in Sport and Society because in the world of popular sport, many people have a host of opinions that they are happy to share. Those opinions may not be as closely tied to an individual's identity as is their outward gendered appearance, as would occur with the material in Gender and Sport, so there is perhaps less risk in sharing ideas in Sport and Society. Within Sport and Society, the higher complexity tasks of cooperative cases and jigsaw necessitated the exploration of multiple viewpoints. Therefore, the consistent variation in perspectives because of the changing seating and group membership was likely an asset. Individuals who disagreed were not stuck together for the entire semester, and those who shared opinions, but were part of different groups, helped to facilitate the large group discussion after small group work ended.

A final thought about seating variation is that they were both clear deviations away from the traditional row and column format. Jankowska and Atlay (2008) discussed three distinct types of learning spaces: the Social Learning space (S-space), the Formal space (F-space), and the Creative space (C-space). As both classes used group work regularly, the physical space became a hybrid of both S-space and F-Space. As each type of space has the potential for great learning (Jankowska \& Atlay, 2008), students learned that during each class they would be exposed to two different spaces that would help them to learn the material. Students learned that the space provided afforded proximity to both peers and the instructor, which may have shaped their belief about what was possible in the learning space (Park \& Choi, 2014). This supports the foundational ideas of ecological psychologists (Ge et al., 2013); if students believe that positive and impactful learning can occur, they are more likely to actively engage in the learning process (Lumpkin et al., 2015b; Park \& Choi, 2014; Zandvliet \& Broekhuizen, 2017), which can be demonstrated by the range of engagement means.

The ICAP framework of interactive, constructive, active, and passive engagement was also supported within this study as tasks are mapped onto the ALIT (Chi \& Wylie, 2014; Van Amburgh et al., 2007). Recall that the ICAP framework argues that in order for meaningful learning to occur, students must cognitively engage with the material rather than just passively receiving it. The lowest level of cognitive engagement in the ICAP, passive, is an example of the zero-complexity task of lecture with PowerPoint. In this study, the lowest scores across both classes were the lecture with PowerPoint task. Even with the different subjects and variations in group formations, lecture was rated the lowest. This is consistent with previous studies discussing the positive impact of active learning strategies (Freeman et al., 2014; Lumpkin et al., 2015a, 2015b; Park \& Choi, 2014; Patrick et al., 2016).

These findings suggest that low-complexity tasks can still impact perceptions of engagement and learning if they fit into the top two levels of the ICAP. Aligning the ALIT tasks with the constructive level of the ICAP results in four activities: question and answer (Task A, low complexity), focused listening (Task B, low complexity), application activity (Task G, low complexity), and small group present/discuss (Task L, moderate complexity). Learning activities within the interactive level of the ICAP include ALIT tasks of defining features matrix (Task O, moderate complexity), debates (Task P, moderate complexity), cooperative cases (Task T, high complexity), and Jigsaw (Task U, high complexity). All of the means for engagement and learning with these various task complexities were found to have statistical significance, which supports the ICAP hierarchy of cognitive engagement.

Within the low-complexity classification, the application activities garnered greater perceptions of engagement and learning when compared with other low-complexity activities. This may have been due to the types of applications asked of students. In reviewing the specific tasks, many of the prompt questions that were asked of students fall into the upper three levels of the HRASE (history, relationships, application, speculation, explanation) questioning hierarchy (Mangram et al., 2015). In Gender and Sport, many times group application activities involved speculation questions, prompting thinking of "what would happen if this was a male athlete instead of a female athlete" or "what are the consequences to the next generation of athletes when they see these behaviors in sport?" Across both classes, the highest level of questioning, explanation, was commonly used, prompting students, for example, to justify the rationale of National Football League owners' decisions or to account for limited visibility of certain sports or types of athletes. Therefore, despite the relative simplicity of the task in which students have to apply one or two concepts to a real-life situation, the type of application that is required needs a higher level of cognition. The greater cognitive engagement draws students closer to the construction of their own knowledge, which is key for longterm learning (Burke et al., 2009; Freeman et al., 2014).

\section{Limitations and Future Research}

As with most applied research, some design elements are beyond researcher control, which introduce flaws in interpreting the results. The learning environments for these two classes were not identical, which introduces uncontrollable variation. Although the classrooms were in fact next to one another, their shape, number of windows, and number of available desks were different. These 
differences could have contributed to student responses about the physical space. In addition, the differences in meeting times likely impacted student levels of actual and perceived engagement with materials. Sport and Society only met two times per week with no regular outside engagement required. Gender and Sport had the online component and the additional face-to-face meeting each month, which required more frequent engagement with the material. There were also different numbers and demographics of students in each class. No demographic information was collected on any student due to the small class sizes. However, research has shown that many student variables have an impact on learning and engagement including temperament, intelligence, and self-esteem (Goldspink \& Foster, 2013), which are compounded by student attitudes, behaviors, and communication styles (Dixson, 2015). By not gathering this information, it is unclear if baseline student differences account for the findings.

When students come late or are impacted by transition time from other classes, they do not have the same opportunity to select an optimal seating location (Park \& Choi, 2014). Although this was not a factor in Sport and Society as students who arrived late would still find their group for the class session, this impacted Gender and Sport. Students self-selected their pods and subsequent desk location early in the semester and their initial choices turned into their mostly permanent seat. Any student who added the class late or who came to class late due to timing elements may not have been able to self-select a group and location that they were truly comfortable with. In addition, no student demographics were utilized in the determination of groups for Sport and Society nor were they used to modify any self-selected groups in Gender and Sport. As found by Park and Choi (2014), students with higher confidence in the class content are less influenced by seating location or peers in the class. Although declaration of major might be an indicator of likely confidence in content, it is not a guarantee. It is also possible that even nonmajors have had multiple classes with some peers who may influence their group work and dynamics.

The data collection instruments and researcher also introduce variation. Only the educational spaces part of the instrument had been evaluated in peer-reviewed research (Zandvliet \& Broekhuizen, 2017); item analysis of the class activities was not applicable as all items were intended to be distinctly different. It is possible that without an additional rater to check the mapping of class activities to the ALIT levels of complexity, the primary researcher erred in the identification of tasks. The use of the instructor as the primary researcher also likely introduces possible bias into the study. Some students were familiar with the instructor from prior classes and others were enrolled for the first time, creating very different levels of familiarity. As this instructor has been on this campus for a number of years and the classes were well established, it is also possible that reputation of the instructor or the course was influencing student responses. This study was conducted at one private institution. Therefore, a single geographic location limits the broad applicability of the findings due to differences in student demographics and backgrounds.

This study was unique compared with other research on student engagement. Existing research on engagement generally uses multiple measures to assess engagement on a single task (e.g., the activity held my attention, the activity aroused my imagination, and the activity was a waste of time) rather than a single measure of engagement for multiple tasks (Athens, 2018; Dixson, 2015; Noel, Stover, \& McNutt, 2015). As the primary focus of this study was to assess differences in task complexity and space, only a single question of engagement was asked.
Engagement was not formally defined within the instrument, which introduces questions of reliability as it allows for individual interpretation of the term. This could be problematic in the analysis of the results as specific engagement behaviors were not explicitly named. Future studies on this topic should include greater depth of engagement behaviors that contribute to the overall means that were captured in this study. Future studies should also include the gathering of additional student factors, such as confidence and attitudes toward learning, which are known to contribute to engagement (Dixson, 2015; Goldspink \& Foster, 2013).

Additional applied research in sport management education is very much needed. Although this study used two classes focused on sport sociology content, research is needed in classrooms of other content areas to assess the impact of active learning strategies and manipulations of physical space. Research conducted in settings that use traditional row and column seating and lecture all of the time can provide an important baseline that was not tested in this study. Inquiry that utilizes a more consistent population would also provide great insights as the needs of majors and nonmajors or first- versus fourth-year students are likely to be highly varied.

Further research is also needed to explore the other ALIT techniques that were not assessed in this study. Approximately half of the techniques were utilized in this particular study, but many others were not. As no high-complexity tasks were utilized in Gender and Sport, there is still a lack of foundational information on the use of these in a sport sociology setting. There would also be great benefit in exploring the progressive blending of low- to highcomplexity tasks over the course of an entire semester and not just the first half.

\section{Conclusion}

This study provides an important step in urging the discipline to more closely examine the pedagogy of teaching and learning. The process of engagement with both peers and content is garnering greater focus in an age of increased higher education accountability. The landscape of higher education is evolving to more closely align with what employers are seeking in new hires rather than value being placed in a traditional liberal arts education. In this age of assessment, content skills only comprise part of the required outcomes; specific soft skills that are needed in the workforce are expected to be modeled in college classrooms. Employers expect graduates to be able to successfully navigate complex working relationships, independently tackle complex tasks, and know how to self-pace. Students in this study reported that they were aware of these interpersonal aspects of learning as a result of the manipulations in physical space. Moving forward, these skills can be developed in the classroom if teachers are willing to explore variations in teaching styles and engagement strategies. To meet the demands of both the 21 st century learner and the 21 st century workforce, it is in the best interest of teachers to reflect on their practices and consider what teaching strategies and design options have the greatest likelihood of maximizing educational achievements.

As classrooms continue to evolve from traditional face-to-face settings into virtual learning spaces, faculty need to consider the many variables that can impact student engagement and learning. In general, there are four variables that should be considered when planning a learning episode: the instructor, the content, the environment, and the student. This study provided some initial insights into how instructors can shape the content and the environment. Moderate-complexity tasks seem to garner higher perceptions of student engagement and learning, although carefully constructed 
application activities, despite their low complexity, can also be effective in these areas. Both manipulations of space were effective in this study, but that is due to the fact that the space was used as a complement to the content. Therefore, instructors should devote some planning time to both areas. The final aspect of the learning episode to consider is what students are bringing into the classroom. The author of this work considers students as part of a "net generation" not because of their birth year, but because they walk into a classroom with a brain like a web browser with 15 different tabs open. These tabs are refreshing at different rates and are each competing for attention and focus. Although instructors hope that at least one of those tabs is attuned to the learning episode, if students are allowed to remain passively engaged in the classroom, there is little assurance that that is the case. By considering space and teaching strategies differently, faculty can assist students in becoming present and engaged.

\section{References}

Athens, W. (2018). Perceptions of the persistent: Engagement and learning community in underrepresented populations. Online Learning Journal, 22(2), 27-58.

Bodary, P.F., \& Gross, M.M. (2018). Innovative teaching and learning strategies in kinesiology. Kinesiology Review, 7(4), 321-327. doi:10. 1123/kr.2018-0037

Bower, G., Hums, M., \& Grappendorf, H. (2015). Same story; different day: Greatest challenges of women working in intercollegiate athletic administration. International Journal of Sport Management, Recreation, \& Tourism, 19, 12-39. doi:10.5199/ijsmart-1791-874X-19b

Brooks, C., \& Solheim, C.A. (2014). Pedagogy matters, too: The impact of adapting teaching approaches to formal learning environments on student learning. New Directions for Teaching and Learning, 2014, 53-61. doi:10.1002/t1.20085

Burke, L.A., Ahmadi, M., \& James, K. (2009). Effectiveness of powerpoint-based lectures across different business disciplines: An investigation and implications. Journal of Education for Business, 84(4), 246-251. doi:10.3200/JOEB.84.4.246-251

Chi, M.T.H., \& Wylie, R. (2014). The ICAP framework: Linking cognitive engagements to active learning outcomes. Educational Psychologist, 49(4), 219-243. doi:10.1080/00461520.2014.965823

Cotner, S., Loper, J., Walker, J.D., \& Brooks, D.C. (2013). "It's not you, it's the room"- Are the high-tech, active learning classrooms worth it? Journal of College Science Teaching, 42(6), 82-88. doi:10.2505/4/ jcst13_042_06_82

Diacin, M.J. (2018). An experiential learning opportunity for sport management students: Manager interview and facility inspection. Sport Management Education Journal, 12(2), 114-116. doi:10.1123/smej. 2017-0033

Dixson, M. (2015). Measuring student engagement in the online course: The Online Student Engagement Scale (OSE). Online Learning, 19(4), 143-157. doi:10.24059/olj.v19i4.561

Eagleman, A.N., \& McNary, E.L. (2010). What are we teaching our students? A descriptive examination of the current status of undergraduate sport management curricula in the United States. Sport Management Education Journal, 4(1), 1-17. doi:10.1123/smej.4.1.1

Freeman, S., Eddy, S.L., McDonough, M., Smith, M.K., Okoroafor, H.J., \& Wenderoth, M.P. (2014). Active learning increases student performance in science, engineering, and mathematics. Proceedings of the National Academy of Sciences of the United States of America, 111(23), 8410-8415. PubMed ID: 24821756 doi:10.1073/pnas. 1319030111
Garrett, N. (2016). How do academic disciplines use powerpoint? Innovative Higher Education, 41, 365-380. doi:10.1007/s10755-016-9381-8

Ge, X., Yang, Y., Liao, L., \& Wolfe, E. (2013). Perceived affordances of a technology-enhanced active learning classroom in promoting collaborative problem solving. In D.G. Sampson, J.M Spector, D. Ifenthaler, \& P. Isaias (Eds.), Proceedings from IADIS 2013: International Conference on Cognition and Exploratory Learning in Digital Age (pp. 359-362). ISBN: 978-989-8533-18-0. Fort Worth, TX.

Goldspink, C., \& Foster, M. (2013). A conceptual model and set of instruments for measuring student engagement in learning. Cambridge Journal of Education, 43(3), 291-311. doi:10.1080/0305764X.2013. 776513

Hayes Sauder, M., \& Mudrick, M. (2018). Student satisfaction and perceived learning in sport management internships. Sport Management Education Journal, 12(1), 26-38. doi:10.1123/smej.2016-0032

Jankowska, M., \& Atlay, M. (2008). Use of creative space in enhancing students' engagement. Innovations in Educational and Teaching International, 45(3), 271-279. doi:10.1080/14703290802176162

Judge, L.W., Pierce, D., Petersen, J., Bellar, D., Wanless, E., Gilreath, E., \& Simon, L. (2011). Engaging experiential service learning through a co-curricular club: The Chase Charlie Races. Journal of Research in Health, Physical Education, Recreation, Sport \& Dance, 6(2), 30-38.

Killian, C.M., \& Woods, A.M. (2018). Expanding learning opportunities in kinesiology through the use of flipped instruction. Kinesiology Review, 7(4), 332-338. doi:10.1123/kr.2018-0046

Komarraju, M., \& Karau, S.J. (2008). Relationships between the perceived value of instructional techniques and academic motivation. Journal of Instructional Psychology, 35(1), 70-82.

Latane, B., Lou, J.H., Nowak, A., Bonevento, M., \& Zheng, L. (1995). Distance matters: Physical space and social impact. Personality and Social Psychology Bulletin, 21(8), 795-805. doi:10.1177/ 0146167295218002

Lei, S.A. (2010). Classroom physical design influencing student learning and evaluations of college instructors: A review of literature. Education, 131(1), 128-134.

Lumpkin, A., \& Achen, R.M. (2015). Flipping a class: Active learning and more of it. Sport Management Education Journal, 9(2), 79-90. doi:10.1123/SMEJ.2014-0042

Lumpkin, A., Achen, R.M., \& Dodd, R. (2015a). Focusing teaching on students: Examining student perceptions of learning strategies. Quest, 67(4), 352-366. doi:10.1080/00336297.2015.1082143

Lumpkin, A., Achen, R.M., \& Dodd, R.K. (2015b). Student perceptions of active learning. College Student Journal, 49(1), 121-133.

Madden, J., Wilks, J., Marone, M., Loader, N., \& Robinson, N. (2012). Journeying together: Understanding the process of teacher change and the impacts on student learning. ISEA, 4O(2), 19-35.

Mangram, J.A., Haddix, M., Ochanji, M.K., \& Masingila, J. (2015). Active learning strategies for complementing the lecture teaching methods in large classes in higher education. Journal of Instructional Research, 4, 57-68. doi:10.9743/JIR.2015.8

Metzger, K.J. (2015). Collaborative teaching practices in undergraduate active learning classrooms: A report of faculty team teaching models and student reflections from two biology courses. Collaborative Teaching Practices, 41(1), 3-9.

Miller, C.J., \& Metz, M.J. (2014). Barriers to the use of researchbased instructional strategies: The influence of both individual and situational characteristics. Physical Review Special Topics- Physics Education Research, 3(2), 020102. PubMed ID: 30305918

Monson, A. (2005). Active learning survey (Unpublished manuscript). Department of Dental Hygiene, Minnesota State University, Mankato.

Noel, D., Stover, S., \& McNutt, M. (2015). Student perceptions of engagement using mobile-based polling as an audience response 
system: Implications for leadership studies. Journal of Leadership Education, 14(3), 53-70. doi:10.12806/V14/I3/R4

Park, E.L., \& Choi, B.K. (2014). Transformation of classroom spaces: Traditional versus active learning classrooms in colleges. Higher Education, 68, 749-771. doi:10.1007/s10734-014-9742-0

Parr, B.B. (2013, July 17). Active voice: Team-based learning in exercise science education. Sports Medicine Bulletin, 1.

Pate, J.R., \& Shonk, D.J. (2015). An experiential learning trip: Exploring student experiences and motivations for volunteering at the super bowl. Sport Management Education Journal, 9(1), 11-24. doi:10. 1123/smej.2014-0001

Patrick, L.E., Howell, L.A., \& Wischusen, W. (2016). Perceptions of active learning between faculty and undergraduates: Differing views among departments. Journal of STEM Education, 17(3), 55-63.

Petersen, C.I., \& Gorman, K.S. (2014). Strategies to address common challenges when teaching in an active learning classroom. New Directions for Teaching and Learning, 2014, 63-70. doi:10.1002/ tl.20086

Safer, A.M., Farmer, L.S.J., Segalla, A., \& Elhoubi, A.F. (2005). Does the distance from the teacher influence student evaluations? Educational Research Quarterly, 28(3), 28-35.
Smith, G.A. (2015). Why college faculty need to know the research about learning. InSight: A Journal of Scholarly Teaching, 10, 9-18.

Van Amburgh, J.A.V., Devlin, J.W., Kirwin, J.L., \& Qualters, D.M., (2007). A tool for measuring active learning in the classroom. American Journal of Pharmaceutical Education, 71(5), 1-8.

van den Berg, Y.H.M., \& Cillessen, A.H.N. (2015). Peer status and classroom seating arrangements: A social relations analysis. Journal of Experimental Child Psychology, 130, 19-34. PubMed ID: 25313926 doi:10.1016/j.jecp.2014.09.007

Van Note Chism, N. (2002). A tale of two classrooms. New Directions for Teaching and Learning, 2002, 5-12. doi:10.1002/tl.74

Yew, T.M., Dagwood, F.K.P., Narayanganj, K., Kampala, M., Jen, L.S., \& Hoya, K.C. (2016). Stimulating deep learning using active learning techniques. Malaysian Online Journal of Educational Sciences, 4(3), 49-57.

Zandvliet, D., \& Broekhuizen, A. (2017). Spaces for learning: Development and validation of the school physical and campus environment survey. Learning Environment Research, 20, 175-187. doi:10.1007/ s10984-017-9228-y 